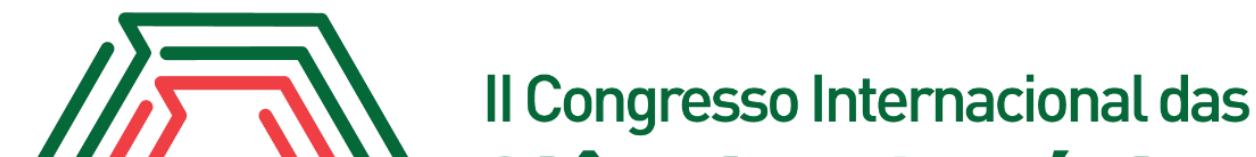 Ciências Agrárias COINTER - PDVAgro 2017
}

\section{EFEITOS DO ESTRESSE HIDRICO EM FEIJÃO CAUPI CRIOULO DA REGIÃO DO CARIRI CEARENSE}

Antonio Jorge Soares Feitosa ${ }^{1}$; Cícero Lucas da Silva ${ }^{2}$; Mateus Gonçalves de Freitas ${ }^{3}$; Paulo André de Sousa Bezerra ${ }^{4}$; Juan Carlos Alvarez-Pizarro ${ }^{5}$

\section{Introdução}

O feijão Caupi (Vigna unguiculata) é atualmente um dos alimentos mais consumidos no Brasil, trata-se de uma rica fonte de proteínas, ferro, potássio e vitaminas do complexo B. Sendo mais produzido principalmente nas regiões Norte e Nordeste, tanto por grandes produtores quanto por agricultores familiares. O estado do Ceará é o maior produtor de feijão caupi do Brasil com a produção equivalente a $20 \%$ do total nacional.

A Embrapa Meio Norte, juntamente com cooperativas de pesquisas e instituições parceiras produzem variedades de feijão caupi sendo cultivado em (1.451.578 ha), que ocupa 30\% da área total que é cultivado no país, com o intuito de geração de renda e emprego. (Embrapa Meio Norte). Porém ainda existe uma demanda por cultivares melhoradas, com maior produtividade e com níveis maiores de tolerância a diversos efeitos bióticos e abióticos.

Vale ressaltar que dentre os efeitos abióticos que podem causar problemas à produção, está o estresse hídrico causado pela falta de água, bem comum em regiões áridas e semiáridas por apresentam baixa pluviosidade. Há diversos estudos com Vigna unguiculata, em que se atribuem a essa espécie características de tolerância à seca, dentro o qual podemos citar SCOTTI-CAMPOS et al (2013).

O presente trabalho teve o intuito de analisar o comportamento da variedade Canapu de feijão caupi crioulo, coletada em cinco locais diferentes da região do Cariri, quando submetido ao déficit hídrico. Analisaram-se os parâmetros agronômicos crescimento da parte aérea e raiz, e um parâmetro fisiológico com relação ao conteúdo relativo de água na folha.

\footnotetext{
${ }^{1}$ Graduando do curso de Agronomia da Universidade Federal do Cariri - antoniojoresoaresufca@gmail.com

${ }^{2}$ Graduando do curso de Agronomia da Universidade Federal do Cariri - cicero lucas@autlook.com

${ }^{3}$ Graduando do curso de Agronomia da Universidade Federal do Cariri - matheusizidorio97@gmail.com

${ }^{4}$ Mestrando do curso de Bioquímica e Biologia Molecular da Universidades Federal do Cariri - pabezerra@alu.ufc.br

${ }^{5}$ Professor Doutor adjunto do curso de Agronomia da Universidade Federal do Cariri - biojcalvarez@ hotmail.com
} 


\section{Fundamentação Teórica}

De modo geral, para lidar com estresses abióticos, as plantas utilizam de três estratégias, sendo esses: escape à deficiência de água, retardo da desidratação e também tolerância à desidratação (SALEHI-LISAR; BAKHSHAYESHAN, 2016).

Em geral, a resistência ao estresse hídrico manifesta-se de quatro formas distintas, entre elas: ajustes fisiológicos, restrição no crescimento, alterações metabólicas e adaptações morfológicas (PINCELLI, 2010).

As respostas da planta à restrição hídrica no solo são influenciadas pela duração e intensidade do estresse, como também pelas condições ambientais de temperatura e umidade relativa; como também, dependem da espécie e cultivar (SAINT-PIERRE et al., 2012).

\section{Metodologia}

O Experimento foi conduzido em casa de vegetação e laboratório de Biologia da Universidade Federal do Cariri UFCA, Centro de Ciências Agrárias e da Biodiversidade CCAB, campus Crato CE em outubro de 2016.

Determinada a capacidade de retenção de água do substrato, definiu-se os tratamentos com $80 \%, 65 \%$ e $50 \%$ da capacidade de campo (cc). Foram estimadas também as perdas diárias por evaporação e suas respectivas lâminas de reposição. Ao $10^{\circ}$ e $14^{\circ}$ dias as plantas foram irrigadas com solução nutritiva de Hoagland.

As sementes foram tratadas com solução de hipoclorito 1:3 durante 5 minutos. Depois lavadas e secadas, a semeadura direta foi realizada com duas sementes por vasos numa profundidade de $2 \mathrm{~cm}$. A coleta do material foi efetuada no $15^{\circ}$ dia retirando os comprimentos da parte aérea e da raiz. Utilizou-se uma régua para analisar o crescimento da planta e balança analítica para se obter o peso da massa fresca da parte aérea e da raiz.

O conteúdo relativo de água foi determinado segundo (SCOTTI-CAMPOS et al. 2013). Através da seguinte formula: $\quad \mathrm{CRA}(\%)=\frac{\mathrm{MF}-\mathrm{MS}}{\mathrm{MT}-\mathrm{MS}} X 100$ Sendo CRA - conteúdo relativo de água; MF - massa fresca; MS - massa seca; MT - peso da massa turgida.

O delineamento experimental foi inteiramente casualizado com esquema fatorial de $3 \times 5$ sendo utilizado cinco variedades de feijão caupi com 5 repetições, totalizando 75 parcelas experimentais. Os dados foram submetidos à análise de variância, as médias comparadas pelo teste Tukey, a 5\% de probabilidade. 


\section{Resultados e Discussões}

Na condução do experimento apenas três variedades de feijão caupi da localidade de Crato, Caldas e Farias Brito foram selecionadas para analisar seu comportamento sob o déficit hídrico, as demais variedades provenientes de Araripe e Independência, obtiveram uma taxa de germinação baixa e o desenvolvimento lento e retraçado.

Figura 1: Crescimento e massa de diferentes variedades de feijão caupi submetidos ao déficit hídrico. Gráfico A - comprimento da parte área. Gráfico B - comprimento da raiz. Gráfico C - massa fresca da parte aérea. Gráfico D - massa fresca da raiz.

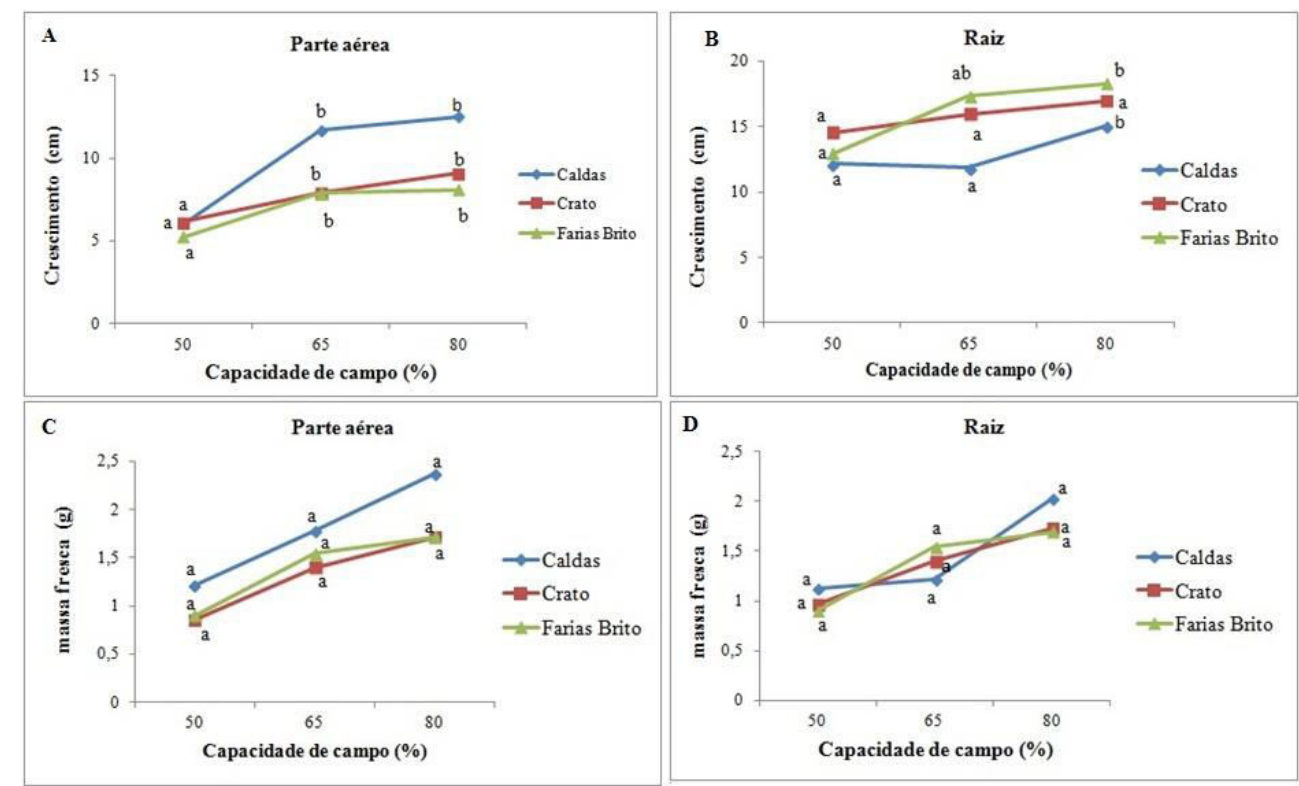

Médias seguidas das mesmas letras minúsculas dentro dos tratamentos, não diferem significativamente, a $5 \%$ de probabilidade pelo teste $\mathrm{t}$.

Houve uma redução do crescimento das três variedades Crato, Caldas e Farias Brito (figura1) sob o tratamento de déficit hídrico com $50 \% \mathrm{cc}$, as plantas cresceram lentamente mostrando diferença estatística comparando com os outros níveis de hidratação de $65 \%$ e $80 \%$ de cc (Gráfico A). Possivelmente a planta não conseguiu produzir fotoassimilados necessários para manutenção do crescimento da mesma sendo um fator evidenciado com o estresse hídrico. (Scalon et al., 2011).

As raízes obtiveram um crescimento maior em relação ao crescimento da parte aérea. Analisando o gráfico (Gráfico B). Nota-se que a variedade de Crato obteve maior crescimento comparado com as outras variedades e não obteve diferença estatística dentre os três regimes de hidratação. Pode-se dizer que a planta sob estresse hídrico, priorizou o crescimento da raiz para absorver água e perder menos água por transpiração (TAIZ \& ZEIGER, 2009). 
O acúmulo da massa fresca da parte aérea e raiz não apresentou diferenças significativas entre os tratamentos tanto na parte aérea quanto na raiz das variedades estudadas. (Gráfico C) e (Gráfico D) Apesar de que as maiores médias foram da variedade de Caldas no tratamento de 80\% da capacidade de campo. (Meira et al., 2017) analisou o parâmetro da massa fresca da raiz em genótipos de feijão caupi e encontrou diferenças significativas entres as variedades BRS Xiquexique e BRS Guariba.

Figura 2: Percentual do conteúdo relativo de água das variedades de locais diferente sob diferentes níveis de capacidade de campo.

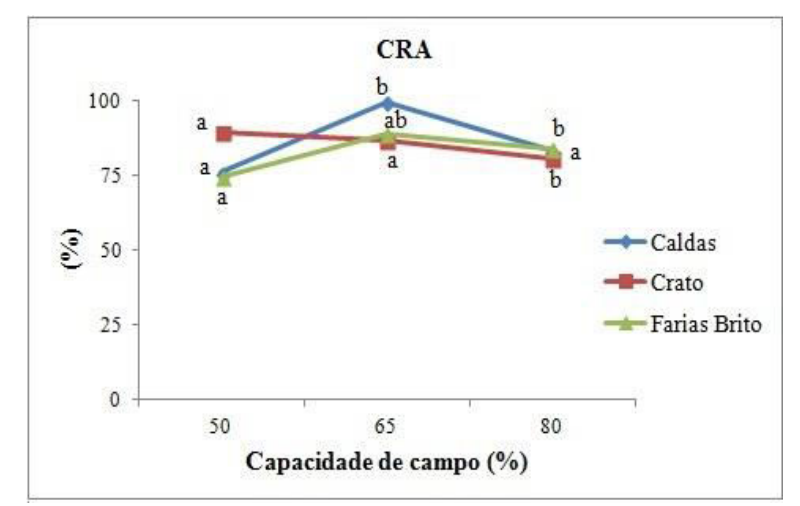

Médias seguidas das mesmas letras minúsculas dentro dos tratamentos, não diferem significativamente, a $5 \%$ de probabilidade pelo teste $\mathrm{t}$.

Para analisar o status hídrico das plantas, pode-se usar o método do conteúdo relativo de água (CRA) em folhas. Na (figura 2) mostra-se o nível de água das três cultivares em percentagem, as mesmas apresentaram diferenças significativas dentro dos tratamentos. A variedade de Crato manteve a hidratação no tratamento com as menores capacidades de campo. Portanto, segundo (Pimentel, C et al., 2002) o CRA é um parâmetro que caracteriza o nível de hidratação da água na planta sendo um melhor indicador do efeito do déficit hídrico na mesma.

\section{Conclusões}

- As variedades de feijão Caupi analisadas em regime de déficit hídrico tem o crescimento das raízes maior que a parte aérea na fase inicial.

- O nível de estresse estabelecido não afetou a produção de massa fresca das plantas.

- As três variedades quando submetidas ao estresse hídrico, mantiveram com seu estado hídrico com um percentual acima de 50\%. 


\section{Referências}

LEITE, L.; Sistema de produção Embrapa. Cultivo de Feijão Caupi. Disponível: https://www.spo.cnptia.embrapa.br. Acesso: 06 out. 2017.

MEIRA, A. et al. Estimativa de parâmetros genéticos para características de crescimento de feião-caupi sob estresse hídrico severo. Agropecuária Científica no Semiárido Centro de Saúde e Tecnologia Rural ACSA, Patos-PB, v.13, n.1, p.41-47, janeiro-março, ISSN: 1808-6845, 2017.

PIMENTEL. C.; Tolerância protoplasmática foliar à seca, em dois genótipos de caupi cultivados em campo. Revista. Universidade. Rural, Serie, Ciências da Vida, Vol.22, n.1, p.07-14, 2002.

PINCELLI, R. P. Tolerância à deficiência hídrica em cultivares de cana-de-açúcar avaliada por meio de variáveis morfofisiológicas. 2010. 20 f. Dissertação (Mestrado em Agronomia). Faculdade de Ciências Agronômicas da UNESP - campus de Botucatu - São Paulo, 2010.

SAINT PIERRE, C.; CROSSA, J. L.; BONNETT, D.; YAMAGUCHI-SHINOZAKI, K.; REYNOLDS, M. P. Phenotyping transgenicwheat for drought resistence. Jounal of Experimental Botany, v. 63, n. 5, p. 1799-1808, 2012.

SALEHI-LISAR, S. Y.; BAKHSHAYESHAN-AGDAM, H. Drought Stress in Plants: Causes, consequences, and Tolerance. In: HOSSAIN, M. A. et al. Drought Stress Tolerance in Plants: Physiology and Biochemistry. New York: Springer International Publishing, v. 1, cap. 1, p. 1-6, 2016.

SCALON. S. et al. Estresse hídrico no metabolismo e crescimento inicial de mudas de mutambo (guazuma ulmifolia lam.). Ciência Florestal, Santa Maria, v. 21, n. 4, p. 655-662, out.dez., 2011.

SCOTTI-CAMPOS. P. et al. Physiological responses and membrane integrity in three Vigna genotypes withcontrasting drought tolerane. Emir. J. Food Agric. 25 (12): 1002-1013, 2013.

TAIZ, L.; ZEIGER, E. Fisiologia Vegetal. 4ª Ed. Porto Alegre: Artmed, 2009. 